\title{
Studies on the Chemical Constituents of Azadirachta indica A. Juss (Meliaceae), Part VII [1]
}

\author{
Salimuzzaman Siddiqui*, Shaheen Faizi, and Bina Shaheen Siddiqui \\ H. E. J. Research Institute of Chemistry, University of Karachi, Karachi-32, Pakistan \\ Z. Naturforsch. 41 b, 922-924 (1986); received September 30, 1985 \\ Azadirachta indica, Meliaceae, 7-Deacetoxy-7 $\alpha$-hydroxyazadiradione
}

A new limonoid, nimbocinol, has been isolated from the fresh, undried, ripe fruits of Azadirachta indica (neem) along with known components, azadirone, epoxyazadiradione, azadiradione, gedunin, 17-hydroxyazadiradione and cholesterol. It is the first report of the isolation of cholesterol from any part of the neem tree.

\section{Introduction}

Azadirachta indica A. Juss (Meliaceae) is indigenous to the Indo-Pakistan subcontinent and its various parts are reputed as therapeutic agents [2,3]. Some of the constituents of neem have recently been shown to possess significant pesticidal activity [4]. More recent studies undertaken on the fresh, undried, uncrushed, ripe and unripe, fruits and the undried leaves of the plant by Siddiqui et al. have led to the isolation and structure elucidation of nine new triterpenoids $v i z$, nimolicinol [5], nimocinol [6], azadirachtol [7], azadirachnol [8], nimbocinone [9], nimocinolide [10], isonimocinolide [10], nimocin [10] and nimolinone [1]; and two new nonterpenoidal components, nimbochalcin [11] and nimbocetin [11].

The present paper deals with the isolation of a new limonoid, nimbocinol (1), from the neem fruits along with known tetranortriterpenoids, azadirone [12], epoxyazadiradione [12], azadiradione (2) [12, 13], gedunin [12], 17-hydroxyazadiradione [13] and a sterol identified as cholesterol. The structure of nimbocinol has been determined as $\mathbf{1}$ through spectral and chemical studies. It has to be mentioned that cholesterol has not so far been reported from any part of the neem tree, although its occurrence has been noted in other plants such as Solanum xanthocarpum [14] and Solanum tuberosum [15].

\section{Results and Discussion}

Nimbocinol (1) has molecular formula $\mathrm{C}_{26} \mathrm{H}_{32} \mathrm{O}_{4}$ (high resolution mass). Its UV spectrum showed maxima at 222 and $237 \mathrm{~nm}$ and the IR spectrum showed peaks at $880,1505,3120$ (furan), $1660(\alpha, \beta$ -

* Reprint requests to Prof. Dr. Salimuzzaman Siddiqui. Verlag der Zeitschrift für Naturforschung, D-7400 Tübingen 0340-5087/86/0700-0922/\$ 01.00/0 unsaturated carbonyl), 1690 (cyclopentenone) and $3450(\mathrm{OH})$. The molecular formula suggested the presence of 11 double bond equivalents, 3 of which have been accounted for by a furan ring, 4 by two $\alpha, \beta$-unsaturated ketone systems and the remaining 4 by the four rings of the nucleus. These suggestions were further supported by the mass spectrum of nimbocinol which showed peaks at m/e 137 (ring-A with $\alpha, \beta$-unsaturated ketone), and $m / e \quad 81$ (ion "a") in addition to peaks at $m / e 408\left(\mathrm{M}^{+}\right), 393(\mathrm{M}-15)^{+}$, $390(\mathrm{M}-18)^{+}, 375(\mathrm{M}-18-15)^{+}, 328(\mathrm{M}-80)^{+}, 309$ $(\mathrm{M}-81-18)^{+}, 299(\mathrm{M}-109)^{+}$and 227 (ion "b"). The base peak at m/e 108 (ion "c") provided crucial evi-

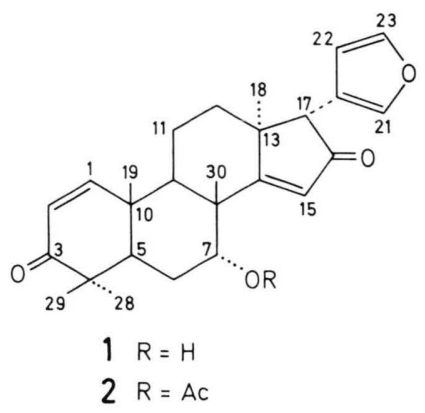

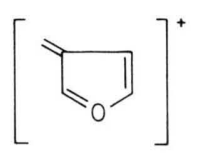

a

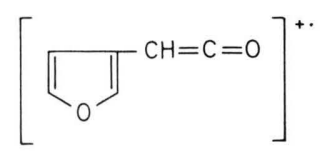

C

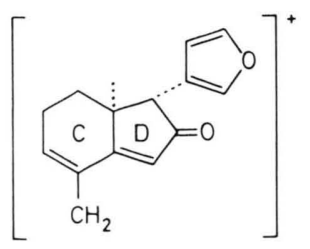

b 
dence regarding the position of the second ketonic function with respect to the furan ring system.

The ${ }^{1} \mathrm{H}$ NMR spectrum (Table I) showed singlets at $\delta 1.05,1.10,1.18,1.23$ and 1.29 (five tertiary methyl groups), two one-proton $\mathrm{AB}$ doublets $(J=$ $10 \mathrm{~Hz}$ ) at $\delta 7.13$ and 5.90 attributable to $\mathrm{H}-1$ and $\mathrm{H}-2$ of 1-en-3-one system of ring- $\mathrm{A}$, three one-proton multiplets at $\delta 6.25(\mathrm{H}-22), 7.50(\mathrm{H}-21), 7.42(\mathrm{H}-23)$ and a one-proton singlet at $\delta 3.47$ (H-17). The signal of $\mathrm{H}-17$ has been broadened due to its allylic coupling with furanic protons. The data recorded so far showed a close structure relationship of nimbocinol with azadiradione (2) [12]. However, in azadiradione, $\mathrm{H}-15$ and $\mathrm{H}-7$ appeared at $\delta 5.83$ and 5.32 respectively, whereas the signals corresponding to the same protons in nimbocinol have been observed at $\delta 6.03$ and $\delta 4.20$, the former signal being distinguished by its sharpness as compared to the signal of $\mathrm{H}-17$. That this downfield resonance of $\mathrm{H}-15$ is due to the hydroxyl function located at C-7, is in accordance with the earlier observations in the case of other tetranortriterpenoids, in which the chemical shift of this proton is strongly influenced by the nature of C-7 functionality and vice versa [12]. The location of the $\mathrm{OH}$ function at $\mathrm{C}-7$ was further supported by the absence of absorbance for the acetate or any other ester function in the IR and ${ }^{1} \mathrm{H}$ NMR spectra. The $\alpha$-orientation (axial position) of the hydroxyl function was established by the narrow width at half height $\left(\mathrm{W}_{1 / 2}=7.5 \mathrm{~Hz}\right)$ of $\mathrm{H}-7$ multiplet.

Table I. ${ }^{1} \mathrm{H}$ NMR spectral data.

\begin{tabular}{lll}
\hline Proton & Nimbocinol (1) & Azadiradione (2) [12] \\
\hline $\mathrm{H}-1$ & $7.13, \mathrm{~d}^{\mathrm{a}}$ & $7.17, \mathrm{~d}^{\mathrm{a}}$ \\
$\mathrm{H}-2$ & $5.90, \mathrm{~d}^{\mathrm{a}}$ & $5.83, \mathrm{~d}^{\mathrm{a}}$ \\
$\mathrm{H}-7$ & $4.20, \mathrm{~m}$ & $5.32, \mathrm{t}$ \\
& $\mathrm{W}_{1 / 2}=7.5 \mathrm{~Hz}$ & $\mathrm{~W}_{1 / 2}=7 \mathrm{~Hz}$ \\
$\mathrm{H}-15$ & $6.03, \mathrm{~s}$ & $5.83, \mathrm{~s}$ \\
$\mathrm{H}-17$ & $3.47, \mathrm{~s}$ & $3.43, \mathrm{~s}$ \\
$\mathrm{H}-21$ & $7.50, \mathrm{~m}$ & $7.45, \mathrm{~m}^{\mathrm{b}}$ \\
$\mathrm{H}-22$ & $6.25, \mathrm{~m}$ & $6.28, \mathrm{~m}$ \\
$\mathrm{H}-23$ & $7.42, \mathrm{~m}$ & $7.45, \mathrm{~m}^{\mathrm{b}}$ \\
$\mathrm{OH}$ & $3.40, \mathrm{~m}$ & - \\
$\mathrm{OCOCH}$ & - & $1.95, \mathrm{~s}$ \\
$\mathrm{Me}$ & $1.29, \mathrm{~s}$ & $1.35, \mathrm{~s}$ \\
& $1.23, \mathrm{~s}$ & $1.19, \mathrm{~s}$ \\
& $1.18, \mathrm{~s}$ & $1.08,6 \mathrm{H}, \mathrm{s}$ \\
& $1.10, \mathrm{~s}$ & $1.03, \mathrm{~s}$ \\
& $1.05, \mathrm{~s}$ &
\end{tabular}

\footnotetext{
${ }^{\text {a }} J=10 \mathrm{~Hz} ;{ }^{\text {b }} 2 \mathrm{H}$ multiplet. All values are in $\delta(\mathrm{ppm})$ relative to $\mathrm{TMS}=0$.
}

Attempted acetylation of nimbocinol with $\mathrm{Ac}_{2} \mathrm{O} / \mathrm{py}$ at room temperature gave back the unchanged starting material, providing chemical evidence for the sterically hindered axial position of the $\alpha$-hydroxyl function. However, when treated with $\mathrm{Ac}_{2} \mathrm{O}$ in the presence of toluene $p$-sulfonic acid nimbocinol afforded an acetate which was identical in every respect (m.p., m.m.p., t.l.c., m.t.l.c., UV, IR, ${ }^{1} \mathrm{H}$ NMR and mass spectra) with azadiradione $[12,13]$. Furthermore, mild alkaline hydrolysis of an authentic sample of azadiradione (2) furnished its deacetyl derivative which was identical with nimbocinol on comparison of its m.p., m.m.p., t.l.c., m.t.l.c. and spectral data (UV, IR, ${ }^{1} \mathrm{H}$ NMR and mass).

All the available spectral data and chemical studies conclusively established that it is a new tetranortriterpenoid with its structure as 7-deacetoxy-7 $\alpha$ hydroxy azadiradione (1). Moreover, the ${ }^{13} \mathrm{C}$ NMR spectral data (Table II) are in agreement with the assigned structure. It may be noted in this connection that isolation of serveral $7 \alpha$-hydroxy tetranortriterpenoids, e.g. $7 \alpha$-obacunol [16], limonol [16], deoxylimonol [16], 7-deacetyl-azadirone [17], -proceranone [17], -gedunin [12], -khivorin [18], -khyanthone (grandifolione) [18] and -photogedunin [19] have previously been reported from different species of Meliaceae and Rutaceae families.

Table II. ${ }^{13} \mathrm{C}$ NMR spectral data.

\begin{tabular}{|c|c|c|c|c|c|}
\hline $\mathrm{C}$ & 1 & 2 & $\mathrm{C}$ & 1 & 2 \\
\hline 1 & 157.5 & 156.7 & 15 & 123.3 & 123.2 \\
\hline 2 & 125.4 & 125.8 & 16 & 205.8 & 204.9 \\
\hline 3 & 204.7 & 203.9 & 17 & 60.5 & 60.7 \\
\hline 4 & 44.0 & 44.0 & 18 & 26.8 & 26.4 \\
\hline 5 & 37.2 & 38.2 & 19 & 18.9 & 18.9 \\
\hline 6 & 22.4 & 23.4 & 20 & 118.3 & 118.4 \\
\hline 7 & 71.4 & 73.8 & 21 & 142.5 & 142.7 \\
\hline 8 & 46.6 & 44.5 & 22 & 111.0 & 111.1 \\
\hline 9 & 44.3 & 46.0 & 23 & 141.4 & 141.6 \\
\hline 10 & 40.0 & 39.9 & 28 & 21.3 & 21.2 \\
\hline 11 & 15.5 & 15.7 & 29 & 26.4 & 26.9 \\
\hline 12 & 31.1 & 30.3 & 30 & 27.7 & 26.2 \\
\hline 13 & 47.7 & 47.9 & $\mathrm{CH}_{3} \mathrm{CO}$ & - & 20.8 \\
\hline 14 & 194.5 & 192.3 & $\overline{\mathrm{C}} \mathrm{H}_{3} \mathrm{CO}-$ & - & 169.5 \\
\hline
\end{tabular}

All values are in $\delta(\mathrm{ppm})$ relative to TMS $=0$.

\section{Experimental}

Melting points were recorded in glass capillary tubes and are uncorrected. IR $\left(\mathrm{CHCl}_{3}\right)$ and $\mathrm{UV}(\mathrm{MeOH})$ 
spectra were measured on JASCO IRA-I and Pye Unicam SP-800 spectrometers respectively. Mass spectra were recorded on Finnigan MAT 112 and 312 double focussing mass spectrometers connected to PDP $11 / 34$ computer system. ${ }^{1} \mathrm{H}$ and ${ }^{13} \mathrm{C}$ NMR (broad band and gated spin echo) spectra were recorded in $\mathrm{CDCl}_{3}$ on a Bruker WP-100-SY-FT-NMR spectrometers with TMS as internal reference. ${ }^{13} \mathrm{C}$ NMR spectral assignments have been made partly through the spin-echo experiments and partly through a comparison of chemical shifts with the published data for similar compounds [13, 17]. The purity of samples was checked on t.l.c. (silica gel).

The ethanolic extract of the fresh, uncrushed, ripe fruits $(20 \mathrm{~kg})$ of neem was divided into acidic and neutral fractions. The latter was subjected to the classical procedures of separation resulting in the isolation of three new triterpenoids, nimolicinol [5], azadirachtol [7], and azadirachnol [8] which have been communicated earlier. The residue obtained on removal of the solvent of the combined mother liquors of these components, was divided into petroleum ether soluble and insoluble fractions. On keeping at room temperature, the former fraction deposited a crystallizate which on recrystallization from ethyl acetate formed aggregates of needles melting at $147-148{ }^{\circ} \mathrm{C}$. It was identified as cholesterol through its m.p., m.m.p., t.l.c., m.t.l.c., comparison of spectral data (IR, HR Mass, ${ }^{1} \mathrm{H}$ NMR and ${ }^{13} \mathrm{C}$ NMR) and the characterization of its acetyl derivative. The petroleum ether insoluble powdery residue was taken in benzene and chromatographed on a column packed with silica gel-60. Elution with benzene followed by benzene ethyl acetate mixtures afforded several fractions. The benzene eluate afforded five known limonoids, azadirone, epoxyazadiradione, azadiradione (2), gedunin, 17-hydroxyazadiradione, while the benzene-ethyl acetate $(99: 1 \mathrm{v} / \mathrm{v})$ fraction gave nimbocinol (1) as a light yellow crystallizate. On recrystallization from methanol it formed colourless needles $(0.2 \mathrm{gm}, 0.1 \%$ on the wt. of the total neutral fraction. m.p. $160-161{ }^{\circ} \mathrm{C},[\alpha]_{\mathrm{D}}^{25}-14.28^{\circ}$ $\left(\mathrm{CHCl}_{3}\right), \mathrm{UV} \lambda_{\max }(\mathrm{MeOH}) \mathrm{nm}: 237$ and 222, IR $v_{\max }$ (KBr) $\mathrm{cm}^{-1}: 3450,3120,2920,1690,1660,1600$, $1505,1380,1160,1020$ and 880 . Mass $(\%) \mathrm{m} / \mathrm{e}: \mathbf{M}^{+}$ 408.2296(13) (calc. for $\left.\mathrm{C}_{26} \mathrm{H}_{32} \mathrm{O}_{4}, 408.2300\right), 393(4)$, $390(15), 375(6), 328(3), 309(3), 299(10), 258(8)$, $241(10), 227(10), 174(30), 137(13), 108(100)$ and 81(26).

\section{Acetylation of nimbocinol (1)}

To $0.1 \mathrm{~g}$ nimbocinol (1), $3 \mathrm{ml}$ of acetic anhydride and $0.1 \mathrm{~g}$ toluene- $p$-sulfonic acid was added and kept at room temperature for $1 \mathrm{~h}$. The reaction mixture on conventional work up furnished the acetyl derivative. It was identified with azadiradione (2) through m.p., m.m.p. and comparison of spectral data (UV, IR, ${ }^{1} \mathrm{H}$ NMR and mass).

\section{Alkaline hydrolysis of azadiradione (2)}

$0.1 \mathrm{~g}$ of azadiradione (2) was kept at room temperature with $6 \%$ ethanolic potash for $40 \mathrm{~min}$. On usual work up it furnished 7-deacetoxy-7 $a$ hydroxyazadiradione, which was found identical with nimbocinol (1) on comparison of m.p., m.m.p., t.l.c., m.t.l.c. and UV, IR, ${ }^{1} \mathrm{H}$ NMR and mass spectral data.
[1] Part VI: S. Siddiqui, B. S. Siddiqui, S. Faizi, and T. Mahmood, J. Chem. Soc. Pak., in press.

[2] W. Dymock, Pharmacographia Indica, Vol. 1, page 89, Hamdard Foundation, Pakistan (1890).

[3] N. R. Pillai and G. Santhakumari, Planta Medica 50, 143 and 146 (1984).

[4] Natural Pesticides from the neem tree. Proceedings of the International neem conference, Rottach-Egern, Federal Republic of Germany, 16-18 June 1980. H. Schmutterer, K. R. S. Ascher and H. Rembold (eds) (Ger. Agency Tech. Coop.: Eschborn, Fed. Rep. Ger.) 297 PP (1981)

[5] S. Siddiqui, S. Faizi, and B. S. Siddiqui, Heterocycles 22, 295 (1984).

[6] S. Siddiqui, B. S. Siddiqui, S. Faizi, and T. Mahmood, Phytochemistry 23, 2899 (1984).

[7] S. Siddiqui, B. S. Siddiqui, and S. Faizi, Planta Medi$\mathrm{ca}$, in press.

[8] S. Faizi, Ph. D. Dissertation, University of Karachi, 1985

[9] S. Siddiqui, T. Mahmood, B. S. Siddiqui, and S. Faizi, Phytochemistry 25, 1986, in press.
[10] S. Siddiqui, S. Faizi, T. Mahmood, and B. S. Siddiqui, J. Chem. Soc. Perkin 1, in press.

[11] S. Siddiqui, T. Mahmood, B. S. Siddiqui, and S. Faizi, Pak. J. Sci. Ind. Res. 28, 1 (1985).

[12] D. Lavie, E. C. Levy, and M. K. Jain, Tetrahedron 27, 3927 (1971)

[13] W. Kraus and R. Cramer, Tetrahedron Lett. 1978, 2395.

[14] G. Kusano, J. A. Beisler, and Y. Sato, Phytochemistry 12, 397 (1973).

[15] K. Schreiber, in R. H. F. Manske (ed.): The Alkaloids, Vol. 10, page 116, Academic Press, New York (1968).

[16] R. D. Bennett and S. Hasegawa, Phytochemistry 21, 2349 (1982).

[17] J. F. Ayafor, B. L. Sondengum, J. D. Connolly, D. S. Rycroft, and J. I. Okogun, J. Chem. Soc. Perkin I 1981, 1750 .

[18] J. D. Connolly, K. L. Handa, R. McCrindle, and K. H. Overton, J. Chem. Soc. (C) 1968, 2227.

[19] M. M. Rao, H. Meshulam, R. Zelnik, and D. Lavie, Phytochemistry 14, 1071 (1975). 